\title{
Clinical significance of HPV-HC2 in diagnosis and prognosis of cervical lesions: a retrospective study
}

\author{
Soule Hassanati, Qin Fang, Yuanyuan Fang, Yan Xing*
}

\begin{abstract}
Department of Obstetrics and Gynecology, Jiangsu Province Hospital, Nanjing Medical University, First Affiliated
\end{abstract} Hospital, Jiangsu Nanjing, China

Received: 01 August 2019

Accepted: 11 September 2019

*Correspondence:

Dr. Yan Xing,

E-mail: 13951891712@163.com

Copyright: () the author(s), publisher and licensee Medip Academy. This is an open-access article distributed under the terms of the Creative Commons Attribution Non-Commercial License, which permits unrestricted non-commercial use, distribution, and reproduction in any medium, provided the original work is properly cited.

\begin{abstract}
Background: To evaluate the human papillomavirus $\mathrm{HC} 2$ different range detection values and their clinical significance in prediction of CIN lesions grades as well as their role in the follow-up outcome after treatment.

Methods: Using the hybrid capture 2 to detect and measure the HPV and the viral load quantity, we enrolled a total of $527 \mathrm{HPV}$ positive women. All patients underwent thin prep liquid-based cytology test (TCT) and only 325 underwent colposcopy guided biopsy due to abnormal cytology results. All cytology and biopsy results were collected and analyzed according to the HPV viral load. Among these patients 108 patients were followed during 2years postoperatives and their prognosis results were collected and analyzed.

Results: The proportion and severity of cytological abnormalities was positively correlated with the HPV-HC2 viral load $(\mathrm{P}<0.05)$. There was a positive correlation between cervical biopsy results and the HPV viral load P <0.05). The more the HPV-HC2 viral load was, the higher CIN2-3 grade percentage was getting. However no statically significant correlation was found between the HPV-HC2 viral load and the follow up outcomes after treatment $(\mathrm{P}>0.05)$.

Conclusions: High HPV-HC2 viral load is significantly associated with the severity of cervical lesions (CIN), however it does not predict any further prognosis on follow-up after treatment.
\end{abstract}

Keywords: Cervical intraepithelial neoplasia, Follow-up, Human papillomavirus, Hybrid capture 2, Viral load

\section{INTRODUCTION}

Human Papillomavirus (HPV) infection is clearly known as the most common cause of cervical intraepithelial neoplasia (CIN) and cervical carcinoma. Generally, the human immune system has the ability to clear up to $90 \%$ of HPV infections within 2 years and only 5 to $10 \%$ may become persistent and lead to high grade CIN or worse. ${ }^{1,2}$ Factors that lead to persistence and progression from infection to cervical intraepithelial neoplasia and then to cervical cancer include the HPV type and HPV viral load. ${ }^{3}$

Hybrid capture 2 ( $\mathrm{HC} 2$ ) is one of the most commonly used testing methods for identifying the presence of HPV infection, and at the same time as semi-quantitative detection of HPV virus.

In fact, the relationship between high HPV-HC2 viral load and grade of CIN lesions is still under debate. Several studies have described the degree of cervical lesions as an increasing function with the HPV-HC2 viral load as dependent variable, while in other investigations, no relationship has been reported. . $^{2,7}$

Therefore, the purpose of our study is designed to explore the correlation between semi-quantitative detection of HPV virus expressed as relative light units (RLU/CO) obtained by using the Hybrid Capture2 (HC2) assay, with the presence and severity of cervical squamous 
intraepithelial lesions, and also to explore the role of HPV viral load in the follow-up monitoring of patients after treatment.

We correlated the HPV viral load detected by HC2 with cytology results, biopsy diagnosis and follow-up results to determine the predictive rule of HPV-HC2 in CIN grade lesions as well as in further prognosis after treatment.

\section{METHODS}

\section{Participants and procedures}

A prospective study was conducted with women who visited the first affiliated hospital of Nanjing medical university from January 2016 to September 2016 for clinical routine evaluation.

Exclusions criteria were pregnancy, history of hysterectomy, having menstruation or infection during evaluation.

Thin prep smears were conducted along with a collection of cervical cells to determine the status of the cervical epithelium. Colposcopy was suggested in patients with abnormal cytological status, and punch biopsy was done if any suspicious lesion was identified. Follow-up was carried out during 2 years post-operatives and results were collected according to biopsies underwent within this period.

This research project was approved by the ethics committee of the first affiliated hospital of Nanjing medical university and written informed consent from participants was not necessary as data were extracted from the patient's register of the department of obstetrics and gynecology. All patients were followed at the first affiliated hospital of Nanjing medical university until the biopsy results were provided.

\section{Assessment of viral load}

HPV viral load was assessed using HC2 assay according to the manufacturer's instructions (QIAGEN, Inc). In HC2 the DNA: RNA hybrids are captured on a microplate, and the emitted light is measured in a luminometer as relative light unit (RLU/CO. Samples were scored negative with an RLU/CO ratio less than 1, and as positive with an RLU/CO ratio up to 1 . Positive cases were identified and a total of 527 patients was recruited and divided into 6 groups according to their $\mathrm{HC} 2$ viral ranges. Grouping characteristics are resumed in Table 1.

Table 1: grouping of patients according to their different viral loads.

\begin{tabular}{|lllllll|}
\hline Subgroups & Group A & Group B & Group C & Group D & Group E & Group F \\
\hline HC2 (RLU/CO) & $1-10$ & $>10-100$ & $>100-200$ & $>200-300$ & $>300-400$ & $>400$ \\
\hline Patients & 147 & 108 & 76 & 63 & 29 & 104 \\
\hline Age* & $39.2 \pm 9.85$ & $39.1 \pm 9.13$ & $40.7 \pm 10.2$ & $41.6 \pm 10.5$ & $41.2 \pm 7.75$ & $40.4 \pm 10.2$ \\
\hline
\end{tabular}

$* \mathrm{P}>0.05$; 1-way analysis of variance (ANOVA) for patients' age.

HC2 $($ RLU/CO $)=$ hybrid capture 2(relative light units/cut-off $)$

\section{Cytological and histological assessment}

Cytological evaluation was performed using liquid-based cytology tests, and results were interpreted according to the criteria set by the 2001 Bethesda system for cervicovaginal cytology reposting: NILM for negative results; and ASC-US, LSIL, ASC-H and HSIL for positive results. Women with abnormal cytology results were recalled for colposcopy examinations and punch biopsies were obtained in women who showed any obvious cervical lesions and taken to the pathology department of the first affiliated hospital of Nanjing medical university.

Results were interpreted as chronic inflammation for negative histological results, CIN1 and CIN2-3 for positive histology results.

\section{Follow-up}

Follow-up was carried out during 2 years post-operative period in 108 patients who underwent LEEP (Loop Electrosurgical Excision Procedure) treatment for CIN2-3 lesions with different HPV viral load. Medical visits were done once in the first post-operative 3 months and subsequently one time every 6 months using Pap smear and HPV hybrid capture test. Recurrent disease was proved by a colposcopy-directed punch biopsy if any lesions required it. Relationship between the viral load and prognosis after treatment was studied.

\section{Statistical analysis}

Statistical analyses were performed using the SPSS software (version 22.0). 1-way analysis of variance 
(ANOVA) was used to analyze the age of women in each group.

The R.C. chi-square test was used with statistical significance defined as two tailed $\mathrm{P}<0.05$ for all tests.

\section{RESULTS}

A total of 527 were enrolled in our study. Table 1 gives an overview of patients' demographic characteristics.
Total mean age of these woman is $40.0 \pm 9.8$ and there was no difference in age among groups $(\mathrm{P}>0.05)$.

\section{Relationships between HPV-HC2 load and cytological results}

The HPV-HC2 and cytology results are summarized in Table 2.

Table 2: Cytology results among patients with different HPV viral load.

\begin{tabular}{|c|c|c|c|c|c|c|}
\hline \multirow{2}{*}{$\begin{array}{l}\text { Cytological } \\
\text { results }\end{array}$} & \multicolumn{6}{|l|}{ Su groups } \\
\hline & Group A & Group B & Group C & Group D & Group E & Group F \\
\hline NILM* & $101 / 147(68.7 \%)$ & $53 / 108(49.1 \%)$ & $30 / 76(39.5 \%)$ & $20 / 63(31.7 \%)$ & $10 / 29(34.5 \%)$ & $34 / 104(32.7 \%)$ \\
\hline ASC-US & $42 / 147(28.6 \%)$ & $43 / 108(39.8 \%)$ & $35 / 76(46.1 \%)$ & $30 / 63(47.6 \%)$ & $8 / 29(27.6 \%)$ & $41 / 104(39.4 \%)$ \\
\hline LSIL & $2 / 147(1.4 \%)$ & $6 / 108(5.6 \%)$ & $4 / 76(5.3 \%)$ & $9 / 63(14.3 \%)$ & $8 / 29(27.6 \%)$ & $21 / 104(20.2 \%)$ \\
\hline ASC-H & $2 / 147(1.4 \%)$ & $4 / 108(3.7 \%)$ & $3 / 76(3.9 \%)$ & $1 / 63(1.6 \%)$ & $2 / 29(6.9 \%)$ & $2 / 104(1.9 \%)$ \\
\hline HSIL* & $0(0.0 \%)$ & $2 / 108(1.9 \%)$ & $4 / 76(5.3 \%)$ & $3 / 63(5.1 \%)$ & $1 / 29(3.4 \%)$ & $6 / 104(5.8 \%)$ \\
\hline total (n) & 147 & 108 & 76 & 63 & 29 & 104 \\
\hline
\end{tabular}

$* \mathrm{P}<0.05$ chi-square test $\quad \mathrm{NILM}=$ negative for intraepithelial lesion or malignancy

ASCUS = atypical squamous cells of undetermined significance;

LSIL= low-grade squamous intraepithelial lesion; HSIL= high-grade squamous intraepithelial lesion

Table 3: Relationship between HPV viral load and histology diagnosis.

\begin{tabular}{|c|c|c|c|c|c|c|}
\hline \multirow{2}{*}{$\begin{array}{l}\text { Histological } \\
\text { diagnosis }\end{array}$} & \multicolumn{6}{|l|}{ Sub groups } \\
\hline & Group A & Group B & Group C & Group D & Group E & Group F \\
\hline $\begin{array}{l}\text { Chronic } \\
\text { inflammation }\end{array}$ & $36 / 53(67.9 \%)$ & $39 / 68(57.4 \%)$ & $18 / 68(34.0 \%)$ & $17 / 44(38.6 \%)$ & $10 / 19(52.6 \%)$ & $35 / 87(40.2 \%)$ \\
\hline CIN1 & $8 / 53(15.1 \%)$ & $9 / 68(13.2 \%)$ & $8 / 53(15.1 \%)$ & $6 / 44(13.6 \%)$ & $1 / 19(5.3 \%)$ & $13 / 87(14.9 \%)$ \\
\hline CIN2-CIN3* & $9 / 53(17.0 \%)$ & $20 / 68(29.4 \%)$ & $27 / 53(50.9 \%)$ & $21 / 44(47.7 \%)$ & $8 / 19(42.1 \%)$ & $39 / 87(44.8 \%)$ \\
\hline total & 53 & 68 & 53 & 44 & 19 & 87 \\
\hline
\end{tabular}

$* \mathrm{P}<0.05$ chi-square test $\quad \mathrm{CIN} 1=$ cervical intraepithelial neoplasia grade1

CIN2-3=cervical intraepithelial neoplasia grade2-3

Table 4: Follow-up results.

\begin{tabular}{|c|c|c|c|c|c|c|}
\hline \multirow{2}{*}{$\begin{array}{l}2 \text { years follow-up } \\
\text { results }\end{array}$} & \multicolumn{6}{|l|}{ Sub groups } \\
\hline & Group A & Group B & Group C & Group D & Group E & Group F \\
\hline $\begin{array}{l}\text { Chronic } \\
\text { inflammation }\end{array}$ & $23 / 22(59.1 \%)$ & $12 / 26(46.2 \%)$ & $4 / 26(25.0 \%)$ & $6 / 12(50.0 \%)$ & $4 / 6(66.7 \%)$ & $15 / 26(57.7 \%)$ \\
\hline CIN1 & $2 / 22(9.1 \%)$ & $6 / 26(23.1 \%)$ & $3 / 26(18.8 \%)$ & $4 / 12(33.3 \%)$ & $1 / 6(16.7 \%)$ & $4 / 26(15.4 \%)$ \\
\hline CIN2-CIN3* & $7 / 22(31.8 \%)$ & $8 / 26(30.8 \%)$ & $9 / 26(56.3 \%)$ & $2 / 12(16.7 \%)$ & $1 / 6(16.7 \%)$ & $7 / 26(26.9 \%)$ \\
\hline total $n$ & 22 & 26 & 16 & 12 & 6 & 26 \\
\hline
\end{tabular}

$* \mathrm{P}>0.05$ chi-square test $\mathrm{CIN} 1=$ cervical intraepithelial neoplasia grade 1

CIN2-3=cervical intraepithelial neoplasia grade2-3

According to these results, an existing relationship between the HPV quantity and the degree of lesions found in cytological test can be seen.

In group A, majority of patients, 101(68.7\%) was observed with normal result NILM and no HSIL lesions was found $0(0.0 \%)$. ASC-US rate was slightly high
(28.6\%), and ASC-H (1.4\%), HSIL (1.4\%) was having the lowest percentages compare to other groups.

As HPV-HC2 quantity increase we noted a significant decreasing of NILM percentages in group $\mathrm{B} ; \mathrm{C} ; \mathrm{D} ; \mathrm{E} ; \mathrm{F}$ $(49.1 \%$; $39.5 \%$; and $31.7 \%$; $34.5 \%$; and $32.7 \%)$, but at the same time a progressively increasing in ASC-US rate 
in groups $\mathrm{A} ; \mathrm{B} ; \mathrm{C} ; \mathrm{D}(28.6 \% ; 39.8 \% ; 46.1 \%$ and $47.6 \%)$, LSIL rate in group $\mathrm{A} ; \mathrm{B} ; \mathrm{C} ; \mathrm{D} ; \mathrm{E} ; \mathrm{F}(1.4 \% ; 5.6 \% ; 5.3 \%$, $14.3 \%, 27.6 \%$; and $20.2 \%)$, ASC-H rate in group $\mathrm{A} ; \mathrm{B} ; \mathrm{C} ; \mathrm{E}(1.4 \% ; 3.7 \% ; 3.9 \%$; and $6.9 \%)$ and also HSIL rate in groups $\mathrm{A} ; \mathrm{B} ; \mathrm{C} ; \mathrm{F}(0.0 \% ; 1.9 \% ; 5.3 \%$; and $5.8 \%)$ was observed. Moreover, analyzing these results using the chi-square test, a $\mathrm{P}$ value $(\mathrm{P}=0.001)$ was found, which confirm a strong evidence of a relationship between the HPV hc2 viral load and the degree of lesion found in cytological test. High HPV-HC2 viral load correlates well with high lesions found in cytology test.

\section{Relationships between HPV-HC2 load and grade of cervical lesions}

Among the patients who underwent colposcopy, a total of 325 patients have a punch biopsy done due to unsatisfied results or the presence of low or high cervical lesions. Results are described as: chronic inflammation for normal results, CIN1, and CIN2-3 for abnormal results. As it is shown in table3, high percentage of chronic inflammation or normal result was found in group A patients $(67.9 \%)$. A decreasing of chronic inflammation rate was observed in group $\mathrm{B} ; \mathrm{C}$; D; $\mathrm{E}$ and $\mathrm{F}$, with HPVHC2 load increasing: $(57.4 \% ; 34.0 \% ; 38.6 \%$; 52.6\%; and $40.2 \%$ respectively).

A slightly elevated of CIN1 percentages was found in all groups $(15.1 \% ; 13.2 \% ; 15.1 \% ; 13.6 \% ; 5.3 \%$; and $14.9 \%$ correspondingly to group A, B, C, D, E, F).

However, a significant increasing rate of CIN2-CIN3 lesions was noticed with HPV-HC2 viral load getting higher, starting from $17 \% ; 29.0 \% ; 50.0 \% ; 47.7 \% ; 42.1 \%$; and $44.8 \%$ for group $\mathrm{A}, \mathrm{B}, \mathrm{C}, \mathrm{D}, \mathrm{E}, \mathrm{F}$ respectively. Briefly, these results are illustrating a positive correlation between HPV-HC2 viral and grade of cervical lesions $(\mathrm{P}=0.011)$. High grade cervical lesions occur with a high level of HPV-HC2 viral load.

\section{Follow-up results}

Follow-up results are given in Table 4. Among 108 patients with different HPV viral load followed after treatment, rate of good prognosis was found, almost high in all groups with the highest rate found in group A $(59.1 \%)$ and in group E $(66.7 \%)$. Recurrence of lowgrade lesion (CIN1) was found with slight elevated percentages in all groups $(9.1 \%$ for group $\mathrm{A} ; 23.1 \%$ for group B; $18.8 \%$ for group C; $33.3 \%$ for group D; $16.7 \%$ for group $\mathrm{E}$; and $15.4 \%$ for group F). High degree lesion CIN2-3 was found with significant rate in all groups especially in group A, B, C $(31.8 \% ; 30.8 \% ; 56.3 \%)$. This shows us that, there is no any dependency noticed between the recurrence and rate of low or high grade CIN lesions with the HPV HC2 results. Prognosis of cervical lesions after treatment was self-directed and completely independent to the HPV viral load $(\mathrm{P}=0.233)$.
Furthermore, combining all our study groups follow-up results together, we have found that of the 108 patients, $54(50 \%)$ have returned to normal, good prognosis, and $54(50 \%)$ have recurrence of CIN lesions. Chance of good prognosis was equal to the chance of redeveloping cervical lesions after treatment and it is not related to the HPV viral load. HPV-HC2 viral load is not a predictive factor of persistence or recurrence of CIN after treatment.

\section{DISCUSSION}

HPV infection is the most important factor in the development of CIN and cervical cancer. Relationships between HPV viral loads and the degree of cervical intraepithelial neoplasia become the objective of many investigations and eventually all those studies still lead to controversial results. In this present study, we aimed to re-investigate the role of HPV viral load in cervical lesions grade and also in the follow-up monitoring after treatment.

Firstly, in our study, high rate of abnormal cytology result was found mostly in women with high HPV viral load. LSIL, ASC-H, HSIL percentages was increasing with HPV viral load getting higher. This is to say that high viral load is a factor which can predict some indications about the cytology outcomes and the severity of cervical lesions that can be found with histological test. ${ }^{8,9}$ This can be supported by a cross sectional study done by Flores $\mathrm{R}$ et al, which showed high HPV viral load, especially for oncogenic types is related to the risk of LSIL and HSIL. ${ }^{10}$ This is also in accordance with several previous studies, where women with lower viral load was mostly found with NILM as result of cytology test and had lower chance for developing CIN2+, contrary with women with a raised viral load who were mostly found with abnormal cytology results, and had a greater chance of developing CIN2+ lesions or more. ${ }^{7,8,11}$

Furthermore, in this study, prevalence of CIN2-3 grade lesions was markedly found in women with higher HPV viral load, comparing to those with a lower viral load who were mostly found with normal results or low-grade lesions. High frequency of biopsy-confirmed CIN2-3 was considerably related to elevated viral load detected by the HC2 assay. Similar results have been demonstrated by M. Origoni although in a different setting. ${ }^{12}$

Another research done in ASCUS women showed a low prevalence of CIN 2-3 among women with RLU ratios less than $10(84.1 \%$ had negative results, $11.1 \%$ had CIN1, and only $3.2 \%$ had CIN2-3). ${ }^{13}$ Possible reasons that can explain the higher prevalence of high grade lesions in high viral load groups may be: chance of clearance of the infection is very diminished in women with higher viral load and that can yield to the persistence of the HPV infection, low regression of cytological abnormalities and then occurrence of cervical lesions or increase severity of the preexisting lesions. ${ }^{6} \mathrm{HPV}-\mathrm{HC} 2$ 
value can be used as a predictive tool for cervical lesions severity.

In this current study, we demonstrated that increasing HPV-HC2 viral load correlates significantly with high abnormal cytological status, and mostly with the increasing of CIN2-3 prevalence, a correlation which can be used for improvement of the detection of high-grade cervical lesions. ${ }^{9}$ However, some investigations have shown that this relationship was depending to the HPV type and genotype, and was mostly related to HPV 16 involvement. ${ }^{4,14}$ In addition persistence of high risk HPV infection is considered as an important reason of cervical lesions progressions and HPV 16 is the most known high risk HPV with long persistence infection period. ${ }^{14-16}$ Unfortunately, this constitutes a limitation in our studies, as we did not get access to cobas HPV test results which could have allowed us to find the contribution of the HPV types in this relations. Viral load detection by the $\mathrm{HC} 2$ assay was shown to be highly sensitive, and the HPVHC2 viral load could be considerably used as a potential marker for predicting the risk for developing higher cervical intraepithelial neoplasia and cervical cancer. ${ }^{14,17}$

It has been demonstrated in some studies that patients treated with high grade CIN have a great chance of redeveloping the disease. Borrai $\mathrm{F}$ et al, has shown that 5 to $15 \%$ of women who underwent treatment for CIN2+ will redevelop the disease within 2 years postoperative. ${ }^{11}$ According to Jeong $\mathrm{NH}, 5$ to $25 \%$ of them will have recurrent disease. ${ }^{18}$ In a recent study, rate of persistence of high grade CIN after treatment was $25.7 \%$ and it has been shown to be mostly associated with persistent HPV 16 infection. ${ }^{19}$ In our study, $50 \%$ of patients with different range of HPV viral load, were having persistent CIN lesions, with $31 \%$ having CIN2-3. Prognosis was strictly independent to the HPV viral load, and chance of recurrence of cervical lesions (CIN1, CIN2-3) or having better prognosis after treatment was almost the same in all patients whatever how high or low their HPV-HC2 viral load was. This is in contrast with Shen G's investigation which showed that HPV-HC2 viral quantity is an effective indicator for the follow-up and prognosis of cervical lesions after treatment. ${ }^{2}$ Recurrence of the disease could be a result of HPV post-infection but not the present infection and viral load as current lesions were entirely removed during operation with a negative margin status.

However, our results can be reinforced by other studies which showed that factors such as HPV-HC2 viral load, HPV genotype are not predictive for recurrence of disease and the only significant factor that could predict the persistence or recurrence of disease was the LEEP positive margin status. ${ }^{20,21}$

\section{CONCLUSION}

In conclusion to our study, there is an existing strong positive correlation between the HPV viral load detected by HC2 assay and the severity of cervical lesions. CIN lesions become severe with intermediate to higher HPV viral quantity. HPV-HC2 can be used as a potential indicator for predicting the risk for developing higher cervical lesions in present illness; however, it cannot be used as a predictor for further follow up and prognosis after treatment.

\section{ACKNOWLEDGMENTS}

Authors would like to thank all the patients from whom our research information were obtained, clinical members of the department of obstetrics and gynecology, cytological laboratory as well as the pathology department of the first affiliated hospital of Nanjing medical university.

Funding: Jiangsu Key Topic of Maternal and Child Health. Award Number: F201718/ Recipient: Yan Xing, $M D$

Conflict of interest: None declared

Ethical approval: The study was approved by the Institutional Ethics Committee

\section{REFERENCES}

1. Peng J, Yuan Y, Shen F, Wang Y, Chen L, Liao DJ, et al. Cervical cancers manifest a high rate of infection by a high-risk human papilloma virus subtype but a very low rate of infection by a low-risk subtype in the Guiyang District of China. J Cancer. 2017;8(7):1263-70.

2. Shen G, Cheng J, Wang Y, Zhou P, Zhang G. Viral DNA load of high-risk human papilloma virus is closely associated with the grade of cervical lesions. Int J Clin Exp Med. 2014;7(12):5826-31.

3. de Sanjosé S, Brotons M, Pavón MA. The natural history of human papilloma virus infection. Best Pract Res Clin Obstet Gynaecol. 2018;47:2-13.

4. Tsai HT, Wu CH, Lai HL, Li RN, Tung YC, Chuang $\mathrm{HY}$, et al. Association between quantitative high-risk human papillomavirus DNA load and cervical intraepithelial neoplasm risk. Cancer Epidemiol Biomarkers Prev. 2005;14(11 Pt 1):2544-9.

5. Xu Y, Dotto J, Hui Y, Lawton K, Schofield K, Hui $P$. High grade cervical intraepithelial neoplasia and viral load of high-risk human papillomavirus: significant correlations in patients of 22 years old or younger. Int J Clin Exp Pathol. 2009;2(2):169-75.

6. Huang MZ, Li HB, Nie XM, Jiang XM, Ming H, Li DQ, et al. Analysis of the dose-response relationship between high-risk human papillomavirus viral load and cervical lesions. Trans R Soc Trop Med Hyg. 2009;103(8):779-84.

7. Lorincz AT, Castle PE, Sherman ME, Scott DR, Glass AG, Wacholder S, et al. Viral load of human papillomavirus and risk of CIN3 or cervical cancer. Lancet. 2002;360(9328):228-9.

8. Demarco M, Lorey TS, Fetterman B, Cheung LC, Guido RS, Wentzensen N, et al. Risks of CIN 2+, 
CIN 3+, and Cancer by Cytology and Human Papillomavirus Status: The Foundation of RiskBased Cervical Screening Guidelines. J Low Genit Tract Dis. 2017;21(4):261-7.

9. Basu P, Muwonge R, Mittal S, Banerjee D, Ghosh I, Panda $\mathrm{C}$, et al. Implications of semi-quantitative HPV viral load estimation by Hybrid capture 2 in colposcopy practice. J Med Screen. 2016;23(2):10410.

10. Flores R, Papenfuss M, Klimecki WT, Giuliano AR. Cross-sectional analysis of oncogenic HPV viral load and cervical intraepithelial neoplasia. Int $\mathbf{J}$ Cancer. 2006;118(5):1187-93.

11. Bottari F, Igidbashian S, Boveri S, Tricca A, Gulmini C, Sesia M, et al. HPV self-sampling in CIN2+ detection: sensitivity and specificity of different RLU cut-off of HC2 in specimens from 786 women. J Clin Pathol. 2017;70(4):327-30.

12. Origoni M, Carminati G, Rolla S, Clementi M, Sideri M, Sandri MT, et al. Human papillomavirus viral load expressed as relative light units (RLU) correlates with the presence and grade of preneoplastic lesions of the uterinecervix in atypical squamous cells of undetermined significance (ASCUS) cytology. Eur J Clin Microbiol Infect Dis. 2012;31(9):2401-6.

13. Jarboe EA, Venkat P, Hirsch MS, Cibas ES, Crum CP, Garner EI. A weakly positive human papillomavirus Hybrid Capture II result correlates with a significantly lower risk of cervical intraepithelial neoplasia 2,3 after atypical squamous cells of undetermined significance cytology. J Low Genit Tract Dis. 2010;14(3):174-8.

14. Wang $\mathrm{W}$, Zhang $\mathrm{XH}$, Li M, Hao $\mathrm{CH}$, Zhao ZM, Liang HP. Association between viral loads of different oncogenic human papillomavirus types and the degree of cervical lesions in the progression of cervical Cancer. Clin Chim Acta. 2018;483:249-55.

15. Liu M, Yan X, Zhang M, Li X, Li S, Jing M. Influence of human papillomavirus infection on the natural history of cervical intraepithelial neoplasia 1: a meta-analysis. Biomed Res Int. 2017;2017:8971059.

16. Dalstein V, Riethmuller D, Prétet JL, Le Bail Carval $\mathrm{K}$, Sautière JL, et al. Persistence and load of highrisk HPV are predictors for development of highgrade cervical lesions: a longitudinal French cohort study. Int J Cancer. 2003;106(3):396-403.

17. Salazar KL, Zhou HS, Xu J, Peterson LE, Schwartz MR, Mody DR, et al. Multiple human papilloma virus infections and their impact on the development of high-risk cervical lesions. Acta Cytol. 2015;59(5):391-8.

18. Jeong NH, Lee NW, Kim HJ, Kim T, Lee KW. High-risk human papillomavirus testing for monitoring patients treated for high-grade cervical intraepithelial neoplasia. J Obstet Gynaecol Res. 2009;35(4):706-11.

19. Byun JM, Jeong DH, Kim YN, Jung EJ, Lee KB, Sung MS, et al. Persistent HPV-16infection leads to recurrence of high-grade cervical intraepithelial neoplasia. Med (Baltimore). 2018;97(51):e13606.

20. Ryu A, Nam K, Kwak J, Kim J, Jeon S. Early human papillomavirus testing predicts residual/recurrent disease after LEEP. J Gynecol Oncol. 2012;23(4):217-25.

21. Niu XY, Feng YK. Early human papillomavirus testing predicts residual/recurrent disease after LEEP risk factors for predicting residual disease in highgrade squamous cervical intraepithelial neoplasia following LEEP conization. Sichuan Da Xue Xue Bao Yi Xue Ban. 2015;46(2):321-5.

Cite this article as: Hassanati S, Fang Q, Fang Y, Xing Y. Clinical significance of HPV-HC2 in diagnosis and prognosis of cervical lesions: a retrospective study. Int J Reprod Contracept Obstet Gynecol 2019;8:4558-63. 